\title{
Factors Predicting Early Release of Thyroid Cancer Patients from the Isolation Room after Radioiodine-131 Treatment
}

\author{
Nosheen Fatima1, Maseeh uz Zaman²*,Areeba Zaman³, Unaiza Zaman ${ }^{3}$, Rabia \\ Tahseen $^{3}$, Wajiha Shahid ${ }^{3}$
}

\begin{abstract}
Background: Patients with differentiated thyroid cancers (DTC) who receive radioactive iodine-131 (RAI) are released from isolation when their dose rate is below the regulatory requirements. The purpose of this study was establish predicting factors for early release from the isolation facility after RAI administration in patients with DTC. Materials and Methods: This was a prospective study which included 96 ( 58 females and 38 males) patients with DTC who had received RAI from April 2013 till August 2015. The study was duly approved by the ethical committee of the institute. Patients who had complete information of primary tumor size (PTS), serum TSH, stimulated thyroglobulin level [sTg] with antibodies (IU/ml) at the time of RAI treatment were included. All had a normal serum creatinine level. To attain lower effective half-life good hydration and administration of soft laxative were ensured. Dose rate was measured (immediately, $24 \mathrm{~h}$ and $36 \mathrm{~h}$ ) at 1 meter distance from anterior mid trunk and a dose rate $<50 \mu \mathrm{Sv} / \mathrm{h}$ was considered as the releasing criterion. At $24 \mathrm{~h} 50$ patients were released while the remaining 46 patients were released at $36 \mathrm{~h}$. A post-ablative whole body scan (PA-WBIS) was performed 5-8 days after RAI ablation in all patients. Results: Patients released after $24 \mathrm{~h}$ were significantly younger, had smaller lesions with higher proportion of papillary cancer, lower $\mathrm{sTg}$, lower $\mathrm{sTg} / \mathrm{TSH}$ ratio and had received a lower dose of RAI as comapred to those who were discharged after $36 \mathrm{~h}$. Serum TSH and gender were not found to have any significant correlation between two cohorts. ROC and multivariate analysis have shown age $\leq 37$ years, $\mathrm{PTS} \leq 3.8 \mathrm{~cm}, \mathrm{RAI} \leq 150 \mathrm{mCi}, \mathrm{sTg} \leq 145 \mathrm{ng} / \mathrm{ml}$ and $\mathrm{sTg} / \mathrm{TSH} \leq 1.085$ as strong indepedent predictors for early release. Conclusions: We conclude that younger age ( $\leq 37$ years), smaller tumor size $(\leq 3.8$ $\mathrm{cm})$, lower RAI dose $(\leq 150 \mathrm{mCi})$, lower $\mathrm{sTg}(\leq 145 \mathrm{ng} / \mathrm{ml})$ and a lower sTg/TSH ratio $(\leq 1.085)$ are significant independent predictors for release at $24 \mathrm{~h}$ after RAI treatment in DTC patients. Effective utilization of these factors could help the treating physicians to use limited number of internment facilities with higher throughput, lower cost and lower psychological stress to patients.
\end{abstract}

Keywords: Radioactive iodine-131 - differentiated thyroid cancer - isolation - early release - dose rate

Asian Pac J Cancer Prev, 17 (1), 125-129

\section{Introduction}

For patients with differentiated thyroid cancers (DTC), including papillary and follicular thyroid carcinoma, (near-)total thyroidectomy followed by the administration of radioiodine-131 (RAI) to destroy any remaining benign or malignant thyroid tissue (i.e. ablation) is the standard of care (Schlumberger 1998). The recommended doses of RAI for ablation by American Thyroid Association (ATA) for low and high risk patients are 30-100 $\mathrm{mCi}$ (1110-3700 $\mathrm{MBq})$ and 100-200 $\mathrm{mCi}(3700-7400 \mathrm{MBq})$ respectively (Cooper et al., 2009). RAI is a reactor produced isotope, has a physical half-life of 8 days and emits high energy gamma rays $(364 \mathrm{KeV}$ ) and beta particles (maximum energy $0.5 \mathrm{MeV}$ ). Beta particles are responsible for $90 \%$ of radiation dose delivered to the patient while remaining $10 \%$ dose is imparted by gamma rays. Radiation exposure from a treated patient to the caregivers and public is mainly caused by gamma rays and also by beta particles in case of surface contamination or accidental ingestion. So patients who are treated with high doses of RAI are the potential source of significant radiation exposure to staff, caregivers and general public. To address this issue, these patients are treated on an in-patient basis and they are admitted in isolation rooms till the radiation dose drops down to the safer or statutory limit. United States Nuclear Regulatory Commission (US-NRC) recommends releasing the patients when residual radioactivity in the body is less than $33 \mathrm{mCi}(<1.2 \mathrm{GBq})$ or a dose rate is less than $7 \mathrm{mrem} /$ hour at 1 meter distance ( $<70$ microSievert/ hour; $\mu \mathrm{Sv} / \mathrm{h}$ ) (Jai et al., 2010). However, based on revised Code of Federal Regulation 10 CFR 35.75, NRC also permits its licensee to administer high doses of RAI on out-patient basis if risk of radiation exposure to a family 
Nosheen Fatima et al

member or caregiver will likely not to exceed $5 \mathrm{mSv}$ (500 mrem) per year (Zaman et al., 2012). However, in most countries, high doses of RAI are administered on in-patient basis and patients are released as per NRC or local regulatory criteria.

The isolation period of patients treated with RAI varies from 1-3 days (Jai et al., 2010) and depends upon the retained activity of administered RAI in patient's body. The magnitude of this retained activity of RAI depends upon the amount of residual functioning thyroid tissue (thyroid bed and distant metastases) and the rate of renal as well as bowel clearance (Barrington et al., 1996). In thyroidectomized patients, the effective half-life of RAI during the first $8 \mathrm{~h}$ (pre-equilibrium period) is considered constant (although some inter-patient variability exists) and is estimated to be 0.8 times the physical half-life, or 6.43 days (Zaman et al., 2012). After the pre-equilibrium period, the remaining RAI is considered to be divided between the thyroidal and the extra-thyroidal components with effective half-lives of 7.3 and 0.32 days respectively (Zaman et al., 2012). The purpose of this study was to find out predicting factors for early release from isolation facility after RAI (radioactive iodine-131) administration in patients with DTC.

\section{Materials and Methods}

This was a prospective study which included 96 (58 females and 38 males) consecutive biopsy proven patients with DTC who attended Nuclear Medicine Department of Ziauddin Hospital Karachi, Pakistan for RAI treatment from April 2013 till August 2015. These patients were primarily referred from The Aga Khan University Hospital (AKUH), Karachi, Pakistan. The study was duly approved by the ethical committee of the institute. We included only those patients who had complete information of primary tumor size (PTS) as mentioned in their histopathology reports, serum TSH (uIU/ml), stimulated thyroglobulin level $[\mathrm{sTg}](\mathrm{ng} / \mathrm{ml})$ with antibodies $(\mathrm{IU} / \mathrm{ml})$ at the time of RAI treatment. All patients had normal serum creatinine level. As per study protocol, these patients were instructed to be on low iodine diet 02 week prior and 3-5 days after RAI treatment. On the day of RAI administration, patients were instructed to come with $02 \mathrm{~h}$ fasting for solid but preferably take at least 01 liter of plain water to ensure good hydration. In isolation room, patients were counseled by nuclear physician and radiation protection officer about the purpose of RAI, benefits of good hydration, bowel clearance and necessary steps after getting RAI to minimize radiation exposure to others. Every patient was provided with 02 liter of plain water to be consumed within $4 \mathrm{~h}$ after oral intake of RAI to ensure shorter biological half-life. In addition they were also given 02 tablespoon of ispaghol husk (stool softener as laxative) after dinner for 03 consecutive nights. Dose rate was measured on all patients at 1 meter distance from anterior mid trunk using digital rate meter (Radiation Alert ${ }^{\circledR}$ Inspector, S.E. international, INC). As per local statutory requirement, patients were released when their dose rate was $<50 \mu \mathrm{Sv} / \mathrm{h}$ at 1 meter distance. Dose rate readings were recorded immediately and $24 \mathrm{~h}$ after RAI administration in all patients. Patients whom dose rate at $24 \mathrm{~h}$ was $<50 \mu \mathrm{Sv} / \mathrm{h}$ were released. In remaining patients, the dose rate lowered down $<50 \mu \mathrm{Sv} / \mathrm{h}$ at $36 \mathrm{~h}$ when they were also released. A post-ablative whole body scan (PA-WBIS) was performed 5-8 days after RAI ablation in all patients using single and dual head gamma cameras (Single Head Ecam, Siemens; Dual Head Discovery GE Healthcare).

Statistical Analysis: Data were analyzed using commercially available packages such as the Medcalc statistical software (MedCalc ${ }^{\circledR}$ Software, Ostend, Belgium), version 11.3.10 and the statistical package for social sciences (SPSS version 17; SPSS Inc., Chicago, Illinois, USA). Comparisons between patient groups were made using the Student t-test for continuous variables and the Chi square test for categorical variables. Continuous variables were described by mean \pm SD. Receiveroperating characteristic curves (ROCs) were plotted for predictive criterion values of age, administered I-131 dose, primary tumor size, serum TSH, sTg and Tg/TSH ratio in carcinoma thyroid patients in correlation with early discharge at $24 \mathrm{~h}$. Odd ratios with $95 \%$ confidence

Table 1. Patients' Demographic

\begin{tabular}{|c|c|c|c|c|}
\hline Varriables & $\begin{array}{l}\text { Total patients } \\
\qquad(\mathrm{n}=96)\end{array}$ & $\begin{array}{l}\text { Patients Discharge } \\
\text { at } 24 \text { hours }(n=50)\end{array}$ & $\begin{array}{l}\text { Patinets Discharge } \\
\text { at } 36 \text { hours }(n=46)\end{array}$ & $\mathrm{p}$ value \\
\hline Age $($ Mean \pm SD) Yrs & $44 \pm 17$ & $40 \pm 17$ & $48 \pm 17$ & $0.0235 *$ \\
\hline Gender (F:M) & $(60: 40 \%)$ & $(60: 40 \%)$ & $(61: 39 \%)$ & \\
\hline Type of Ca (Pap:Foll) & $71: 25: 00$ & 44:06:00 & $27: 19: 00$ & $0.0026 *$ \\
\hline $\begin{array}{l}\text { Size of primary tumor } \\
(\text { Mean } \pm \mathrm{SD})(\mathrm{cm})\end{array}$ & $4.138 \pm 2.673$ & $3.292 \pm 1.901$ & $4.494 \pm 3.052$ & $0.0216^{*}$ \\
\hline $\begin{array}{l}\text { Serum TSH (IU/L) } \\
\text { (Median with range) }\end{array}$ & $\begin{array}{c}72.012 \\
(0.05->150)\end{array}$ & $\begin{array}{c}79.241 \\
(8.76->150)\end{array}$ & $\begin{array}{c}59.985 \\
(0.05->150)\end{array}$ & 0.2601 \\
\hline $\begin{array}{l}\text { Serum } \mathrm{Tg}(\mathrm{ng} / \mathrm{ml}) \\
\text { (Median with range) }\end{array}$ & $\begin{array}{c}52.5 \\
(0.02->6000)\end{array}$ & $\begin{array}{c}12.5 \\
(0.02->6000)\end{array}$ & $\begin{array}{c}430 \\
(0.33->6000)\end{array}$ & $<0.0001 *$ \\
\hline $\begin{array}{l}\text { Serum } \mathrm{Tg} / \mathrm{TSH} \text { ratio } \\
\text { (Median with range) }\end{array}$ & $\begin{array}{c}0.983 \\
(0.0001-12000)\end{array}$ & $\begin{array}{c}0.17 \\
(0.0001-130.434)\end{array}$ & $\begin{array}{c}5.418 \\
(0.003-12000)\end{array}$ & $<0.0001 *$ \\
\hline $\mathrm{I}-131$ adminstred dose $(\mathrm{Mean} \pm \mathrm{SD})(\mathrm{mCi})$ & $139 \pm 39$ & $122 \pm 29$ & $157 \pm 40$ & $<0.0001 *$ \\
\hline $\begin{array}{l}\text { Exposure rate } 24 \mathrm{hrs} \text { after dose administration } \\
(\mathrm{Mean} \pm \mathrm{SD})(\mathrm{uSv} / \mathrm{hr})\end{array}$ & $50.582 \pm 37.309$ & $26.885 \pm 11.002$ & $76.339 \pm 38.790$ & $<0.0001 *$ \\
\hline $\begin{array}{l}\text { Exposure rate } 36 \mathrm{hrs} \text { after dose administration } \\
(\mathrm{Mean} \pm \mathrm{SD})(\mathrm{uSv} / \mathrm{hr})\end{array}$ & $29.613 \pm 12.433$ & ----- & $36.234 \pm 12.366$ & $<0.0001 *$ \\
\hline
\end{tabular}

$\mathrm{SD}=$ Standard Deviation; F=Female; TSH=Thyroid stimulating hormones; M=Male; Tg=Thyroglobulin; Pap=Papillary Ca; ${ }^{*}<<0.05 ;$ Foll=Follicular Ca 
Factors Predicting Early Release of Thyroid Cancer Patients from the Isolation Room after Radioiodine-131 Treatment

interval and $\mathrm{Z}$ statistics were calculated based on criterion values of respective predictive factors. P-values less than 0.05 were considered significant.

\section{Results}

Study cohort consisted of biopsy proven 96 patients (mean age $44 \pm 17$ years, F: M, 60\%:40\%) of DTC (71 papillary cancer and 25 follicular carcinoma) with a mean PTS of $4.138 \pm 2.673 \mathrm{~cm}$. Median serum TSH and sTg levels were $72.012 \mathrm{uIU} / \mathrm{mL}$ (range: 0.05 - >150) and $52.500 \mathrm{ng} / \mathrm{ml}$ (range: 0.02 - >6000) respectively. Low median serum TSH and higher median sTg levels were seen in patients with significant residual tissue over neck with or without functioning metastases on post-ablative whole body iodine scan. Median sTg/TSH ratio was 0.983 while mean dose of RAI administered was 139 $\pm 39 \mathrm{mCi}(5143 \pm 1443 \mathrm{MBq})$. Mean dose rates $(\mathrm{uSv} / \mathrm{h})$ immediately, 24 and $36 \mathrm{~h}$ after RAI administration were $126.085 \pm 74.702$ (96 patients), $50.582 \pm 37.309$ (96 patients) and $36.234 \pm 12.366$ (46 patients) [Table 1] On the basis of discharging criteria (dose rate $<50 \mathrm{uSv} / \mathrm{h}$ at 1 meter), 50 patients were released after $24 \mathrm{~h}$ dose rate measurement while 46 patienst were released after $36 \mathrm{~h}$ when their dose rate was below the statutory limit. Patients who were discharged after $24 \mathrm{~h}$ were significantly

Table 2. Tumors' Demographics

\begin{tabular}{|c|c|c|c|c|}
\hline $\begin{array}{l}\text { Pre-op } \\
\text { TNM } \\
\text { staging }\end{array}$ & patients & $\begin{array}{c}\text { Patients } \\
\text { Discharge } \\
\text { at } 24 \text { hours }\end{array}$ & $\begin{array}{c}\text { Patinets } \\
\text { Discharge } \\
\text { at } 36 \text { hours }\end{array}$ & $\mathrm{p}$ value \\
\hline & $(n=96)$ & $(n=50)$ & $(n=46)$ & \\
\hline $\mathrm{T} 1$ & $22(23 \%)$ & $16(32 \%)$ & $06(13 \%)$ & $0.0488 *$ \\
\hline $\mathrm{T} 2$ & $30(31 \%)$ & $21(42 \%)$ & $09(20 \%)$ & $0.0358 *$ \\
\hline $\mathrm{T} 3$ & $29(30 \%)$ & $10(20 \%)$ & $19(41 \%)$ & $0.0435 *$ \\
\hline $\mathrm{T} 4$ & $15(16 \%)$ & $03(06 \%)$ & $12(26 \%)$ & $0.0156^{*}$ \\
\hline NO & $38(40 \%)$ & $30(60 \%)$ & $08(17 \%)$ & $<0.0001 *$ \\
\hline N1a & $25(26 \%)$ & $08(16 \%)$ & $17(37 \%)$ & $0.0350 *$ \\
\hline N1b & $33(34 \%)$ & $12(24 \%)$ & $21(46 \%)$ & $0.0404 *$ \\
\hline M0 & $75(78 \%)$ & $45(90 \%)$ & $30(65 \%)$ & $0.0068 *$ \\
\hline M1 & $21(22 \%)$ & $05(10 \%)$ & $16(35 \%)$ & $0.0068 *$ \\
\hline \multicolumn{5}{|c|}{ Post Ablative Scan Findings } \\
\hline \multicolumn{5}{|l|}{ Negative } \\
\hline Positive & $04(04 \%)$ & $02(04 \%)$ & $02(04 \%)$ & 0.6022 \\
\hline Thyroid bed & $42(44 \%)$ & $35(70 \%)$ & $07(15 \%)$ & $<0.0001 *$ \\
\hline Neck Nodes & $31(32 \%)$ & $09(18 \%)$ & $22(48 \%)$ & $0.0035^{*}$ \\
\hline Distant Mets & $19(20 \%)$ & $04(08 \%)$ & $15(33 \%)$ & $0.0050 *$ \\
\hline
\end{tabular}

younger, had smaller lesions with higher proportion of papillary cancer, lower sTg, lower sTg/TSH ratio and had received a lower mean dose of RAI as comapred to those who were discharged after $36 \mathrm{~h}$ (Table 1). They also had significanly lower dose rates immediatley and at $24 \mathrm{~h}$ after administration of RAI compared to those who were discharged after $36 \mathrm{~h}$. Serum TSH and gender were not found to have any significant correaltion between two cohorts (Table 1).

Regarding post-opertaive tumor, node and metastasis (pTNM) status, Table 2 shows about $2 / 3$ rd of patients in early relaese group had a lesion size $<4 \mathrm{~cm}$ (T1 and T2) and $60 \%$ had negative nodes and $92 \%$ had no evidence of distant metastasis on PA-WBIS. Similarly patients in delayed release had T3-4 lesion (67\%) with positive nodes in $83 \%$ and distant metastasis was seen in $33 \%$ on PA-WBIS.

We also used receiver operator characteristic (ROC) curve to find out the cut-off value of age, dose of RAI, PTS, TSH, sTg, sTg/TSH to discriminate between early and delayed discharge of patients after RAI administration (Figure 1). ROC analysis revealed that age $\leq 37$ years, PTS $\leq 3.8 \mathrm{~cm}, \mathrm{RAI} \leq 150 \mathrm{mCi}, \mathrm{sTg} \leq 145 \mathrm{ng} / \mathrm{ml}$ and $\mathrm{sTg} / \mathrm{TSH}$ $\leq 1.085$ had highest discriminatory power for predicting early discharge. Serum TSH level was not found to have any significant impact upon early discharge of patients (Table3).

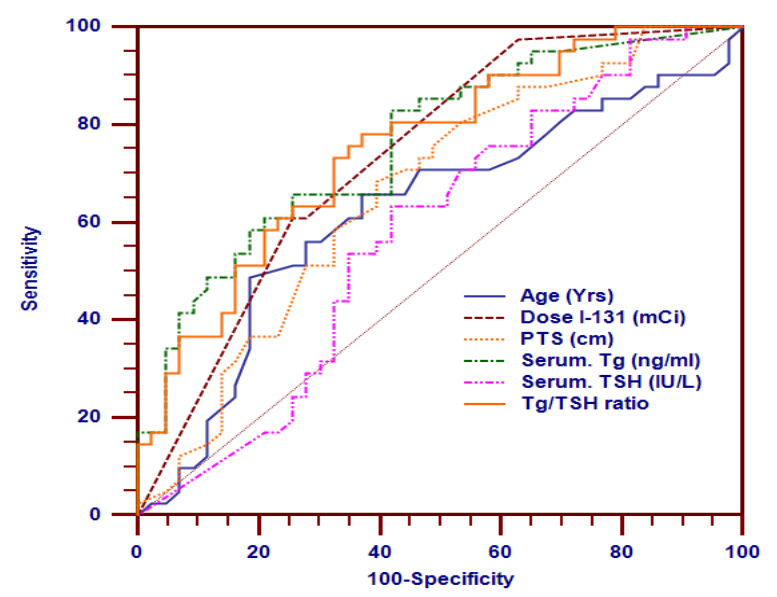

Figure 1. Receiver Operating Characteristics analysis of age, administered I-131 dose, primary tumor size, serum TSH, Tg and Tg/TSH ratio in Ca thyroid patients in correlation with early discharge at 24 hours

Table 3. Receiver Operating Characteristics Analysis of Age, Administered I-131 dose, Primary Tumor Size, Serum TSH, Tg and Tg/TSH Ratio in Ca Thyroid Patients in Correlation with Early Discharge at 24 hours

\begin{tabular}{|c|c|c|c|c|c|c|c|c|}
\hline Test Variables & AUC & Criterion & Sensitivity & Specificity & SE & $\begin{array}{l}95 \% \text { Confi } \\
\text { lower limits }\end{array}$ & $\begin{array}{l}\text { nce Interval } \\
\text { upper Limits }\end{array}$ & $P$ value \\
\hline Age (years) & 0.638 & $<=37$ Years & $58 \%$ & $73.90 \%$ & 0.058 & 0.534 & 0.734 & $0.0175 *$ \\
\hline PTS (cm) & 0.663 & $<=3.8 \mathrm{~cm}$ & $68.30 \%$ & $60.50 \%$ & 0.059 & 0.552 & 0.763 & $0.0063 *$ \\
\hline $\begin{array}{l}\text { I-131 dose } \\
(\mathrm{mCi})\end{array}$ & 0.743 & $<=150 \mathrm{mCi}$ & $96 \%$ & $41.30 \%$ & 0.047 & 0.644 & 0.827 & $0.0001 *$ \\
\hline Serum Tg (ng/ml) & 0.78 & $<=145$ & $82 \%$ & $60.90 \%$ & 0.046 & 0.684 & 0.858 & $0.0001 *$ \\
\hline $\begin{array}{l}\text { Serum TSH } \\
(\mathrm{IU} / \mathrm{L})\end{array}$ & 0.559 & $>16.75 \mathrm{IU} / \mathrm{L}$ & $96 \%$ & $19.60 \%$ & 0.06 & 0.454 & 0.66 & 0.325 \\
\hline $\mathrm{Tg} / \mathrm{TSH}$ ratio & 0.763 & $<=1.085$ & $72 \%$ & $69.60 \%$ & 0.048 & 0.666 & 0.844 & $0.0001 *$ \\
\hline
\end{tabular}

AUC=Area Under Curve; PTS=Primary tumor size; SE=Standard Error; *p<0.01 
Nosheen Fatima et al

Multiple logistic regression analysis revealed that age $\leq 37$ (odds ratio; $\mathrm{OR}=3.913$ ), $\mathrm{PTS} \leq 3.8 \mathrm{~cm}(\mathrm{OR}=$ $2.171)$, dose of $\mathrm{RAI} \leq 150 \mathrm{mCi}(\mathrm{OR}=4.250)$, serum $\mathrm{Tg}$ $\leq 145 \mathrm{ngm} / \mathrm{ml}(\mathrm{OR}=7.086), \mathrm{Tg} / \mathrm{TSH} \leq 1.085(\mathrm{OR}=5.333)$ and papillary histopathology $(\mathrm{OR}=5.160)$ were found to be strong independent factors for early release after RAI administration. However, gender and serum TSH $>16.67$ did not find to have contributory effect for early discharge (Table 4).

\section{Discussion}

RAI treatment has beein playing a pivotal role in the management of patients with DTC for more than half a century (Chung 2002). Radiation exposure caused by high energy gamma rays and risk of contamination by beta particles of RAI are the major concern for caregivers, staff and general public. In Pakistn as per Pakisatn Nuclear Regulatory Authority (PNRA) requirement, patients receiving $\mathrm{RAI}>30 \mathrm{mCi}(1110 \mathrm{MBq})$ must be admitted in isolation and release once dose rate at 1 meter is $<50$ $\mu \mathrm{Sv} / \mathrm{h}$. In this prospective study we have evaluated the predictive values of various factors for early discharge from isolation room after RAI administration.

Patients in early release group were relatively younger than the delayed release group and better renal function in younger patients was considered as one possible reason for shorter effective half life. This is a well established fact that renal clearance of RAI is sluggish in patients with thyroid hormone withdrawl than euthyroid who received rTSH due to better glomerular filtration rate in later group (Papadimitriou et al., 2006; Borget et al., 2008). However, there are published studies showing a mean effective half life of $15.7 \mathrm{~h}$ in hypothyroid patients with no significant impact of age (Remy et al., 2008). This fact indicates possible role of other contributory factors as well. Our data also show no significant impact of gender upon the release timings of patients. Although the study by Remy et al (Remy et al., 2008) has shown a longer effective half life in male than female patients who received RAI for thyroid cancer due to an aggressive course of disease in males. The observed discordance could by explained by different female to male ratio in our study was 60\%:40\% than 80\%:20\% in Remy's study. In our study follicular histopathology and large PTS were also found to be associated with delayed release after RAI administration. This could be explained by more advance disease associated with larger PTS and an established aggressive course of folliclular lesion due to their hematogenous route of spread (Zaman et al., 2012). Another important aspect of our study was significantly higher proportion of follicular lesions than the reported incidence (Xhaard et al., 2014). This is also in contradiction to our previous report (Zaman et al., 2012) and could be due to referral bias as $30 \mathrm{mCi}(1110 \mathrm{MBq})$ dose of RAI is preferred by local endocrinologists for low risk patients with a PTS $<4$ $\mathrm{cm}$ with papillary histopathology. Although serum TSH level had no statistically significant correation between early and delayed released patients, but the level was lower in later group. This was due to presence of larger amount of residual tissue over thyroid bed with or without functioning metastases (noted on PA-WBIS) as lowest value of TSH was appreciably lower in patients released after $36 \mathrm{~h}$. No significant direct association between serum TSH and effective half life has also been reported by other researcher (Remy et al., 2008). This notion is also supported by significantly higher levels of STg (thyroid specific tumor marker depicting burden of functioning thyroid tissue in body) and higher $\mathrm{sTg} / \mathrm{TSH}$ ratio in patients released at $36 \mathrm{~h}$. In this study patients received higher doses of RAI were released late due to the dose rate at $24 \mathrm{~h}$ was greater than statutory requirement and this is explained by a longer effective half life in these patients with larger residual functioning thyroid tissue evident by their sTg levels and PA-WBIS which is also reported in other publihsed studies (Menzel et al., 2003; Travis and Stabin 2006; Remy et al., 2008).

ROC curve revealed that age $\leq 37$ years and a PTS $\leq 3.8 \mathrm{~cm}$ were found to have significant discriminatorty value for predicting early release from isolation. This could be explained by better renal clearance in younger population and lower risk of extrathyroidal disease and distant metastasis associated with smaller tumor size which means smaller bulk of residual functioning tissue in these thyroidectoized patients (Machens et al., 2005). The higher OR of these predicotrs also denote their role as independent predictor for early release. A sTg level $\leq 145 \mathrm{ng} / \mathrm{ml}$ and $\mathrm{sTg} / \mathrm{TSH}$ ratio $\leq 1.085$ also provided a cut-off to differentiate patients with lower burden of residual functioning tissue and their high OR also signify their independent roles as predicotr for early release. RAI dose $\leq 150 \mathrm{mCi}$ was found to be a independent predicting factor with significant diganostic value for early release in our study. Although reprotedly effective half life has no correlation with dose of RAI (Remy et al., 2008), it is possible that lower disease bulk in these patients could be the major contributory factor. Intrestingly gender and serum TSH level were not found significant impact upon early release of patients. Although male gender is considered as a risk factor for DTC and we do not have a tangible explanation for this finding in our study. However, we would like to emphasize upon the clinical significance of these cut-off values for treating physicans who could predict and plan accordingly the logistic of isolation rooms in a busy clinical setup.

In this study we did not measure urinary iodine concentration nor any dosimetry was performed for precise calculation of effective half life of RAI . We know this is a major limitation but we also understand that primary objective of our study was to find out predicting factors for early release after RAI administration in patients with DTC.

Findings of our study would be important for treating nuclear physicians to utilize their treatment facilities in an efficient way to accommodate more patients waiting to receive RAI treatment. Many countries including Pakistan, where RAI tretament ( $>30 \mathrm{mCi}$ ) has to be given in isolation as per statutory requirement, have limited inpatient facilities. Occupancy of limited facilities for 3-5 days contributes to increase in waiting time and significant delays in administration of RAI treatment and this has a significant negative impact on survival of these patients 
Factors Predicting Early Release of Thyroid Cancer Patients from the Isolation Room after Radioiodine-131 Treatment

(Higashi et ., 2011). Furthermore, prolong internment also enhances the treatment cost and has its own psychological and logistic impacts on families and patients too (Zaman et al., 2012). We feel that treating physicians could predict the expected stay of their patients in isolation based on predicting factors mentioned in our study. This would indeed provide a better flexibility for efficiently using the limited number of isolation rooms for more patients at a lower cost and lower psychological stress due to shorter internment period.

We conclude that younger age ( $\leq 37$ years), smaller tumor size $(\leq 3.8 \mathrm{~cm})$, lower RAI dose $(\leq 150 \mathrm{mCi})$, lower $\mathrm{sTg}(\leq 145 \mathrm{ng} / \mathrm{ml})$ and a lower $\mathrm{sTg} / \mathrm{TSH}$ ratio $(\leq 1.085)$ are significant independent predictors for release at $24 \mathrm{~h}$ after RAI treatmnet in DTC patients. Effective utilization of these factors could help the treating physcians to use limited number of internment facilities with higher throughput, lower cost and lower psychological stress to patients.

\section{References}

Barrington SF, Kettle AG, Doherty GM, et al (1996). Radiation dose rates from patients receiving iodine-131 therapy for carcinoma of the thyroid. Eur J Nucl Med, 23, 123-30.

Borget I, Remy H, Chevalier J, et al (2008). Length and cost of hospital stay ofradioiodine ablation in thyroid cancer patients: comparison between preparationwith thyroid hormone withdrawal and thyrogen. Eur J Nucl Med Mol Imaging, 35, 1457-63.

Chung JK (2002). Sodium iodide symporter: its role in nuclear medicine. J Nucl Med, 43, 1188-200.

Cooper DS, Doherty GM, Haugen BRL, et al (2009). Revised American thyroid association management guidelines for patients with thyroid nodules and differentiated thyroid cancer. Thyroid, 19, 1167-214.

Higashi T, Nishii R, Yamada S, et al (2011). Delayed initial radioactive iodine therapy resulted in poor survival in patients with metastatic differentiated thyroid carcinoma: a retrospective statistical analysis of 198 cases. J Nucl Med, 52, 683-9.

Jai HL, Seok GP (2010). Estimation of the Release Time from Isolation for Patients with differentiated thyroid cancer treated with high-dose I-131. Nucl Med Mol Imaging, 44, 241-5.

Menzel C, Kranert WT, Dobert N, et al (2003).rhTSH stimulation before radioiodinetherapy in thyroid cancer reduces the effective half-life of 131I. J Nucl Med, 44, 1065-68.

Machens A, HolzhausenHJ, Dralle H (2005). The prognostic value of primary tumor size in papillary and follicular thyroid carcinoma. Cancer, 103, 2269-73.

Papadimitriou D, Sofia K, Loukia O, et al (2006). Differentiated thyroid cancer: comparison of therapeutic iodine-131biological elimination after discontinuation of levothyroxine versusadministration of recombinant human thyrotropin. AnnlNucl Med, 20, 63-7.

Remy H, Borget I, Leboulleux S, et al (2008). 131I Effective half-life and dosimetry in thyroid cancer patients. $J \mathrm{Nucl}$ Med, 49, 1445-50.

Schlumberger MJ (1998). Papillary and follicular thyroid carcinoma. New Engl J Med, 338, 297-306.

Travis CC, Stabin MG (2006). 131I ablation treatment in young females after the Chernobyl accident. $J$ Nucl Med, 47, 1723-27.

Xhaard C, Ren Y, Clero E, et al (2014). Differentiated thyroid carcinoma risk factors in French Polynesia. Asian Pac $J$ Cancer Prev, 15, 2675-80.

Zaman M, Fatima N, Sajjad Z, Hashmi I (2012). High dose I-131 therapy on outpatient basis: imperative and no more a desire. PJNM, 2, 50-56

Zaman M, Fatima N, Sajjad Z, et al (2012). Threshold primary tumour sizes for nodal and distant metastases in papillary and follicular thyroid cancers. Asian Pacific J Cancer Prev, 13, 2473-76. 